\title{
Genetic study of hepatitis B virus in Indonesia reveals a new subgenotype of genotype $B$ in east Nusa Tenggara
}

\author{
Neni Nurainy $\cdot$ David H. Muljono \\ Herawati Sudoyo $\cdot$ Sangkot Marzuki
}

Published online: 9 July 2008

(C) Springer-Verlag 2008

Erratum to: Arch Virol (2008) 153:1057-1065

DOI 10.1007/s00705-008-0092-z

In the above-mentioned article, there was an error in Figure 2 appearing on page 1062: B7 in the column Gtp was incorrectly stated as B6. The correct Figure 2 should have appeared as shown below.

The online version of the original article can be found under doi:10.1007/s00705-008-0092-z.

N. Nurainy · D. H. Muljono $(\bowtie) \cdot H$. Sudoyo $\cdot$ S. Marzuki

Eijkman Institute for Molecular Biology,

Jl. Diponegoro 69, Jakarta 10430, Indonesia

e-mail: davidhm@eijkman.go.id

N. Nurainy

Department of Research and Development,

PT Bio Farma, Jl Pasteur No. 28,

Bandung 40161, Indonesia 


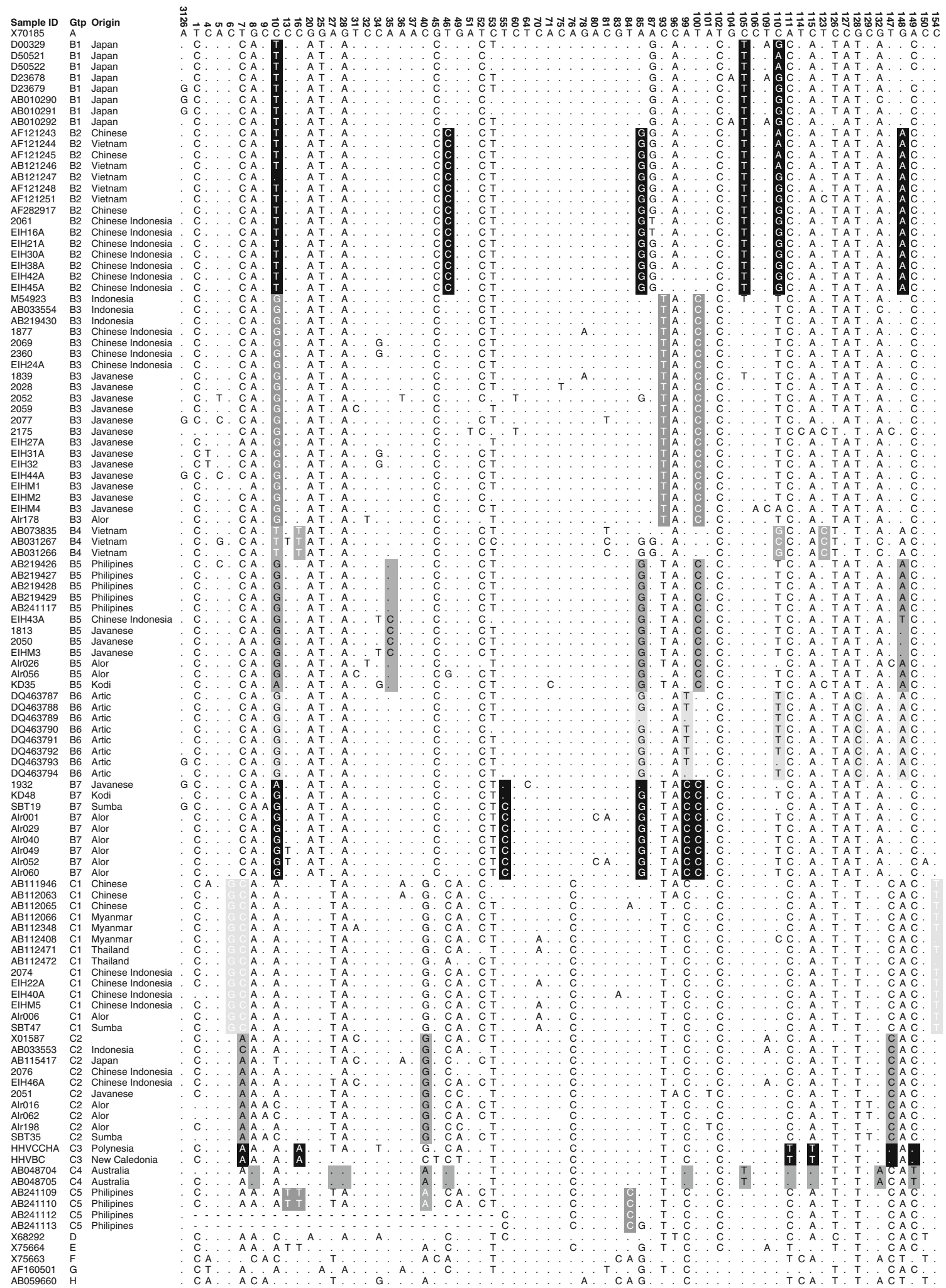

Fig. 2 Single nucleotide polymorphisms (SNPs) in the Pre-S2 region show signatures of HBV genotypes and subgenotypes. The SNPs identified in the Pre-S2 region of HBV sequences examined in Fig. 1 and in 47 newly generated sequences (Materials and methods) are shown, grouped based on their genotypes and population origins. Dots indicate nucleotides identical to those of the genotype A sequence, used as the reference sequence. Twelve SNPs (T1C, T7C, G8A, C10T/G/A, G28A, T52C, C53T, T102C, A111C, C115A, C126T, and A149C) distinguish HBV/B and HBV/C from HBV/A. SNPs specific to genotypes and subgenotypes are highlighted 